\title{
Filme com cenas de violência: efeito sobre o comportamento agressivo de crianças expresso no enredo de uma redação
}

\author{
Ana Presicla Batista \\ Lídia Fukahori \\ Verônica Bender Haydu \\ Universidade Estadual de Londrina
}

\begin{abstract}
RESUMO
A violência na mídia e seus efeitos sobre o comportamento agressivo têm recebido grande atenção de diversos segmentos da sociedade. Os efeitos de um filme com cenas de violência sobre o comportamento agressivo de crianças foi investigado por meio da diferença no grau de agressividade expresso em redações feitas antes e após o filme. Vinte e cinco meninas e trinta e um meninos de $4^{\mathrm{a}}$ série do Ensino Fundamental, de uma escola pública, participaram de um experimento com um delineamento intra-grupo. Primeiro, as crianças redigiram uma redação, a partir de um enredo que iniciava uma estória. Após 24 h, elas assistiram ao filme Mortal Kombat exibido em sala de aula; e finalmente elas redigiram uma outra estória, a partir de um enredo diferente. As redações foram julgadas por três estudantes universitários que não conheciam o objetivo do estudo. Eles atribuíram notas de 0 a 10 para o grau de agressividade dos personagens das estórias, com base em critérios pessoais. A análise dos dados indica que a agressividade expressa nas redações pelas meninas e pelos meninos aumentou após eles terem assistido ao filme. Estes resultados indicam que assistir filmes com cenas de violência afeta o comportamento de crianças de ambos os sexos, quando avaliado por meio de redações.
\end{abstract}

Palavras-chave: filme com violência; comportamento agressivo; violência na mídia.

\section{ABSTRACT \\ Films with violent scenes: effect on children's agressive behavior as expressed written compositions}

Media violence and its effects on aggressive behavior have been a concern of several segments of society. The effects of a film with violent scenes on the aggressive behavior of children was investigated, by evaluating the difference in the level of aggressiveness expressed in compositions written before and after watching such a film. Twenty five girls and thirty one boys, aged from 9 to 12 years old and of the $4^{\text {th }}$. grade of a public fundamental school, participated in a experiment with intragroup design. First, all the children wrote a composition, given a particular plot which would begin the story. The film Mortal Kombat was subsequently shown in the classroom, and within 24 hours they wrote another story, with a different beginning plot. The compositions were judged by three university students who did not know the purpose of the study. They scored the character's aggressiveness in the composition on a scale from 0 to 10 , using their own judgment and criteria.. Analysis of this data indicated that the aggressiveness expressed on composition by girls and boys increased after watching the film. The difference was larger for boys than for girls. These results show that watching films with violent scenes increases aggressive behavior in children of both genders, when evaluated through means of written composition.

Keywords: violent films; aggressive behavior; media violence.

\section{INTRODUÇÃO}

Uma grande parte dos brasileiros passam diversas horas do dia vendo televisão, assistindo a vídeos ou filmes, ou ainda envolvidos com jogos eletrônicos e Internet. Uma pesquisa ${ }^{1}$, realizada no período de julho a agosto de 1997, sobre "Os padrões de controle da assistência de TV, vídeo e cinema por crianças e adolescentes", publicada no livro "A televisão e a violência: o impacto sobre a criança e o adolescente", cuja organização técnica foi feita por Zavaschi (1998), revelou que as crianças e os jovens brasileiros gastavam em média $3 \mathrm{~h} 57$ min diárias assistindo TV e que $91 \%$ gastavam pelo menos $1 \mathrm{~h}$ diária nessa atividade. Entre as questões que surgem diante desse quadro, algumas são: Qual o papel da mídia no dia-adia das pessoas? Qual o impacto da mídia de massa no comportamento de interação social da criança e do jovem?

Os pais entrevistados nessa pesquisa divergem quanto ao valor que atribuem à influência que a TV exerce no processo educativo; alguns consideraram ser um "mal necessário" que ajuda e atrapalha, enquanto outros julgaram-na como "essencialmente prejudicial, posto que [é] conflitante com os valores da família". Entre as justificativas relativas às avaliações negativas destacam-se as seguintes: 
- programação considerada inadequada, ao veicular, sem qualquer critério, temáticas polêmicas (sexo, drogas), sendo responsável por uma certa distorção da realidade;

- antecipação de temas e problemas (homossexualismo, traições, subornos, violência $25 \%$, drogas, prostituição), reduzindo o período de inocência, o que, acreditam, pode gerar problemas comportamentais no futuro;

- usurpação do tempo de convívio familiar, avaliação esta identificada mais intensamente junto àqueles que possuem diversos aparelhos, fazendo com que a audiência assuma um caráter individualizado, na medida em que os filhos assistem TV em seus quartos, dificultando desta forma sua regulação e acompanhamento. (Zavaschi, 1998, Seção: Valores sociais e meios de comunicaçã̃o de massa - Principais resultados, 10)

Em síntese, os dados quantitativos mostram que:

Entre aqueles que apontam espontaneamente que a TV atrapalha a educação dos filhos, verifica-se que o principal problema se volta para o fato de atrapalhar o horário dos estudos/fazer com que não queiram estudar (42\%); sendo também citada a veiculação excessiva de programas violentos (13\%); faz com que as crianças sejam indisciplinadas/sem limites (9\%); influências nas atitudes (9\%) $e$ mostra cenas de sexo/eróticas/pornográficas (8\%). (Destaques no original). (Zavaschi, 1998, Seção: Valores sociais e meios de comunicação de massa Principais resultados, 20)

O tema referente ao efeito da violência na mídia sobre o comportamento das crianças e dos jovens torna-se cada vez mais importante porque, ao mesmo tempo em que cresce o acesso desse grupo etário a esses meios de comunicação e de entretenimento, cresce também o índice de cenas de violência exibidas ou praticadas virtualmente. Bushman e Anderson (2001) relataram que, a análise de conteúdo de mais de $8 \mathrm{~h}$ de programas de TV a cabo e de canais abertos nos EUA revela que em $60 \%$ dos programas há a ocorrência de eventos violentos. Em uma outra pesquisa (Yokota \& Thompson, 2000), na qual foi avaliado, de forma sistemática, o índice de cenas de violência em 74 desenhos animados classificados como destinados à audiência em geral (G-rated, for general audiences), lançados inicialmente no cinema, como, por exemplo, The Lion King e Toy Story, foi constatado que todos os filmes têm pelo menos um ato de violência e que ocorre um total de 125 ferimentos, incluindo 62 fatais, em $62 \%$ dos filmes. Resultados semelhantes foram encontrados por Thompson e Haninger (2001) ao avaliarem 55 jogos de computador, classificados como destinados a qualquer pessoa (E-rated, for everyone): 64\% envolvem violência intencional, para uma média de $30,7 \%$ de tempo de jogo; e $44 \%$ dos jogos. Apesar de não identificados como apresentando conteúdos violentos, contêm atos de violência.

A importância dada ao fato de que a violência na mídia pode contribuir para o desenvolvimento da agressividade e/ou de comportamentos anti-sociais fica evidente nas mais diversas manifestações encontradas na mídia de massa brasileira, que foram acessadas na internet, como, por exemplo, em: "Desenhos animados podem ser prejudiciais aos seus filhos"; "A violência virtual"; "Livro mostra os efeitos da violência na mídia", texto em que o livro "A Criança e a violência na mídia" é comentado; e no discurso "Violência na mídia", proferido pelo representante da UNESCO, no Brasil (Werthein, 1999), no lançamento dos livros "A Criança e a violência na mídia" e "Inocência em Perigo", em Brasília. Apesar de haver um grande número de reportagens sobre o assunto, quando se está interessado em dados empíricos sobre a realidade brasileira, verifica-se que em quase todas as reportagens/discursos não são apresentados dados sobre as práticas do público brasileiro, mas somente sobre as do público dos EUA. Dentre as poucas pesquisas brasileiras, encontra-se aquela publicada no livro anteriormente citado (Zavaschi, 1998) em que é apresentado um capítulo com o relato da que foi encomendada pela UNESCO, realizada com crianças e jovens brasileiros. Os demais capítulos, no entanto, foram organizados com base em fontes estadunidenses, como o próprio texto aponta no capítulo intitulado "Fontes de informação".

Ainda, dentre as pesquisas desenvolvidas com a população brasileira, destacam-se dois outros estudos. Um deles foi realizado em 1998, com crianças da cidade de Belo Horizonte (MG), por Lourenço e Jinzenji (2000). Trata-se de uma réplica das pesquisas feitas entre 1929 e 1944, por Helena Antipoff, e uma outra feita em 1993, por Regina Helena de Freitas Campo, as quais tiveram como objetivo principal investigar o efeito que a ênfase da mídia ao consumismo produz sobre os ideais das crianças. Lourenço e Jinzenji apresentam tabelas, nas quais são comparados de forma direta os dados que foram coletados nas décadas de 20,30, 40 e 90, as quais mostram que houve uma mudança acentuada na indicação das crianças quanto aos modelos que elas consideram atrativos. $\mathrm{O}$ recorte dessas informações permite observar o contraste entre os cenários presentes nas décadas de 20 a 40 e os da década de 90 . Nas décadas de 20 a 40, “(...) a família era apontada pelas crianças, de um modo geral, como a grande agência fornecedora de modelos, seguida pela escola, na pessoa da professora e dos colegas, e da igreja, na pessoa de Deus, Jesus e de santos" (p. 41). As crianças, em 1998, consideram como modelos identificatórios, em primeiro lugar, artistas de televisão e cinema, cantores e atletas, pessoas com quem elas têm contato por meio da mídia. Essa tendência foi registrada tanto em relação às meninas (47\%), quanto aos meninos $(37,2 \%)$.

O outro estudo foi realizado por Gomide (2002) e teve como objetivo identificar o número de horas semanais que crianças e adolescentes assistem televisão. Os participantes eram estudantes de colégios particulares e estaduais da cidade de Curitiba (PR), com idade variando de 7 a 17 anos. Esse levantamento visou fornecer subsídios à Comissão da Criança e do Adolescente da OAB-PR, para a elaboração de um Projeto de Lei, que regulamenta a programação infantil da TV brasileira. Os dados 
demonstram que os estudantes entrevistados $(n=825)$ assistem, em média, 26,46 h semanais de TV, sendo que os programas assistidos, segundo a avaliação de especialistas, não se configuram como recomendados para essa população.

O contraste na quantidade de estudos sobre padrões de hábitos do público brasileiro e estadunidense não se restringe a esse aspecto, referente ao levantamento de dados sobre hábitos, mas, encontra-se presente, também, no âmbito das pesquisas científicas, que buscam estabelecer a relação entre violência na mídia e o desenvolvimento de comportamento agressivo, e/ou de comportamentos anti-sociais de expectadores, e/ou jogadores. O grande número de pesquisas empíricas publicadas nos EUA e na Europa pode ser acessado por meio de inúmeras revisões bibliográficas, como por exemplo, Freedman (1984); Comstock e Strasburger (1990), Wood, Wrong e Chachere (1991); Paik e Comstock (1994); Hughes e Hasbrouck (1996); Dill e Dill (1998); Griffiths (1999); Pennell e Browne (1999); Bushman e Anderson (2001) e Villani (2001) ${ }^{2}$.

Quanto às pesquisas realizadas no Brasil, uma busca no Scielo $^{3}$ e no INDEXPSI ${ }^{4}$ possibilitou a identificação de apenas dois artigos. Um deles descreve um estudo desenvolvido por Menandro e Gueiros (1994), o qual teve como objetivo investigar a diferença nas concepções acerca de violência de pessoas que locam filmes com cenas de agressão retaliadora, quando comparadas às que locam filmes comuns. Um questionário foi inserido nas caixas de filmes selecionados e solicitou-se que fossem desenvolvidos na própria locadora onde foram obtidos. Os locadores de filmes contendo violência reconhecem-se como mais agressivos. Eles "propuseram mais freqüentemente, para determinados personagens sociais, punições intensas e ilegais; revelaram acreditar menos na recuperação de outros personagens; e exibiram uma concepção mais tolerante quanto ao desrespeito aos direitos humanos" (p. 4).

Gomide (2000) descreve uma pesquisa na qual foram avaliados os efeitos de filmes com cenas de violência sobre o comportamento agressivo de crianças, em uma situação que promoveu oportunidades para a ocorrência de conflitos interpessoais. Dois experimentos foram conduzidos, nos quais filmes com cenas de violência e filmes considerados não-violentos foram exibidos a crianças de 9 a 11 anos de idade, e o comportamento delas foi observado em jogos de futebol de salão. Os times de futebol eram formados por participantes do mesmo sexo, que jogavam sempre contra participantes também do mesmo sexo. Em cada um dos dois experimentos participaram 160 crianças, sendo 80 meninos e 80 meninas. No Experimento 1, os participantes foram distribuídos em quatro grupos: o Grupo 1 assistiu ao filme TimeCop - O Guardião do Tempo, considerado um filme violento, com herói; o Grupo 2 assistiu ao documentário Kids, que apresenta violência contra e entre adolescentes; o Grupo 3 assistiu ao filme Águas Perigosas, em que há situações de cooperação entre os personagens; e o Grupo 4 era o grupo controle. No Experimento 2, os participantes foram distribuídos em dois grupos: o
Grupo 1 assistiu ao filme com cenas de violência praticada por heróis e uma heroína - Mortal Kombat e o Grupo 2, ao filme sem violência - Babe, um Porquinho Atrapalhado. A variável dependente era formada por categorias de comportamento agressivo, previamente definidas, observadas em um esquema de registro de intervalo.

No Experimento 1, cada tipo de filme teve um efeito específico sobre o comportamento dos participantes. Após assistirem aos filmes Timecop e Kids, os meninos apresentaram índices superiores de comportamentos agressivos, quando comparados com os do grupo controle e aos que foram apresentados pelas meninas. As meninas que assistiram ao filme Kids apresentaram mais agressividade do que as do grupo controle, mas não as que assistiram ao filme TimeCop. Não foi registrada diferença entre o grupo controle e os participantes de ambos os sexos, após assistirem ao filme Aguas Perigosas.

No Experimento 2, a forma de mensuração do comportamento agressivo foi a mesma que a do experimento anterior. Após assistirem ao filme Mortal Kombat, com cenas de violência, os participantes apresentaram mais agressividade do que antes da exibição do filme e maior, também, em relação ao apresentado após o filme Babe, um Porquinho Atrapalhado, o qual não apresenta cenas de agressividade. A análise em separado dos dados dos meninos e das meninas mostra que o índice de comportamentos agressivos das meninas não mudou após o filme Mortal Kombat. Os grupos de ambos os sexos não apresentaram diferença antes e após a exibição do filme Babe, um Porquinho Atrapalhado. A autora concluiu que filmes com cenas de violência de luta aumentam o comportamento agressivo de crianças do sexo masculino, mas não as do sexo feminino. Com base nos dados do Experimento 1, Gomide sugere que, quando as cenas de violência dos filmes envolvem abusos físico, psicológico e/ou sexual, o comportamento agressivo de meninas também é afetado. Esse último aspecto é assinalado pela autora como requerendo ser mais bem investigado.

Um outro aspecto, que pode ter contribuído para a diferença no efeito dos filmes em relação ao gênero, pode estar relacionado com o tipo de variável dependente selecionada, para análise. Gomide (2000) observou o comportamento das crianças em uma partida de futebol de salão. Apesar de o futebol ser um esporte amplamente difundido no Brasil, não é o tipo de atividade comum entre as meninas, seja nas horas de lazer, seja nas escolas, como parte das aulas de Educação Física. Como não foi feito um levantamento da diferença com que os participantes desse estudo praticavam futebol, não se pode avaliar até que ponto esse aspecto possa ter contribuído para a diferença nos resultados entre os dois gêneros.

Visando produzir dados empíricos, que permitam avaliar o efeito de filmes com cenas de violência sobre o comportamento de crianças brasileiras e obter, assim, evidências adicionais para a conclusão apresentada por Gomide (2000) e investigar se com o registro de uma outra definição para a variável dependente, possivelmente, ocorra a redução do efeito relacionado às diferentes histórias de vida dos dois 
gêneros, foi proposto o presente estudo que replicou parcial-mente o procedimento do Experimento 2 de Gomide. O procedimento proposto diferiu, portanto, quanto à variável dependente registrada: em vez de serem

observados os comportamentos agressivos das crianças durante um jogo de futebol de salão, usou-se uma medida baseada na agressividade expressa em estórias fictícias. Enredos ambíguos, que iniciavam estórias que as crianças deviam completar, foram fornecidos antes e após o filme com cenas de violência ${ }^{5}$. Este tipo de variável dependente foi utilizado em um estudo anterior (Bushman \& Anderson, 2002), no qual foi demonstrado que jogar videogames violentos, por 20 minutos, aumenta significativamente a ocorrência de pensamentos, sentimentos e comportamentos agressivos, por parte dos personagens de estórias completadas por estudantes universitários.

O objetivo do presente estudo consistiu, portanto, em verificar se o filme Mortal Kombat, que apresenta cenas de violência praticadas por personagens de ambos os sexos, aumenta o grau de agressividade expresso no enredo de estórias redigidas por crianças de 9 a 12 anos, do Ensino Fundamental.

\section{MÉTODO \\ Participantes}

Participaram 56 alunos de $4^{\mathrm{a}}$ série do Ensino Fundamental, de uma escola pública. Entre as crianças, 25 eram do sexo feminino e 31 do sexo masculino, com idades variando entre 9 a 12 anos. Três estudantes universitários do sexo feminino, que cursavam o terceiro ano de graduação em Psicologia e que não conheciam o objetivo do estudo, participaram como juízes para avaliar redações escritas por esses alunos.

\section{Materiais}

Um aparelho de televisão, um videocassete, uma fita de vídeo e dois textos com enunciados, para iniciarem a redação, foram previamente elaborados pelos pesquisadores. A fita de vídeo continha o filme de ficção Mortal Kombat - O Filme, produzido por Larry Kasanoff e dirigido por Paul Anderson, com duração de 98 minutos, que retratava um torneio chamado Mortal Kombat, ocorrido em Hong Kong, por meio do qual, o protagonista teria a chance de vingar a morte de seu irmão e salvar o mundo. Os personagens coadjuvantes Sônia e Johny Cage eram lutadores e os três foram escolhidos para lutar contra o inimigo Shang Tsung. Durante um torneio, os lutadores superaram seus medos, tornaram-se amigos e conseguiram derrotar o inimigo, salvando, dessa forma, a Terra.

O texto utilizado antes do filme (enredo 1) foi o seguinte: "Cacá foi passar alguns dias na casa de uma tia desconhecida e era muito grande a sua curiosidade para conhecer aquela casa enorme. Percorreu todos os cômodos e ao entrar no porão percebeu que o trinco quebrou e a porta ficou trancada, então...". O texto utilizado após a exibição do filme (enredo 2) foi: "Os pais de Tatá tiveram que fazer uma longa viagem e a criança teve que passar algum tempo em uma creche onde...".

\section{Procedimento}

Os participantes foram instruídos a desenvolver o enredo de uma estória, com aproximadamente 20 linhas, dispondo de tempo livre, cujo início foi estabelecido pelos experimentadores (Enredo 1). A redação foi realizada em uma das salas de aula da escola, em sessão coletiva.

Quarenta e oito horas após terem redigido a redação, os participantes assistiram ao filme Mortal Kombat. Logo após o término do filme, os participantes foram solicitados a redigir uma outra estória, a qual iniciou com um enredo distinto do anterior (enredo 2).

As redações produzidas foram avaliadas pelos três juízes, que não conheciam os objetivos do estudo. Eles foram instruídos a classificar o grau de agressividade expresso por escrito nas redações e, para tanto, deveriam atribuir notas numa escala de 0 a 10, para a agressividade apresentada no texto pelos personagens das estórias, tendo como base seus critérios pessoais. As redações feitas antes e após o filme foram entregues aos juízes de forma embaralhada e eles foram instruídos a registrar as notas em folhas separadas, de tal forma, que cada juiz não tinha acesso à nota atribuída pelo outro.

\section{RESULTADOS}

Os dados referentes às notas atribuídas pelos juízes às redações feitas pelos participantes, dada sua natureza, foram tratados por meio de estatística nãoparamétrica.

A Figura 1 mostra a mediana do grau de agressividade atribuído pelos juízes às redações de meninos e meninas, antes e depois de terem assistido ao filme Mortal Kombat. 


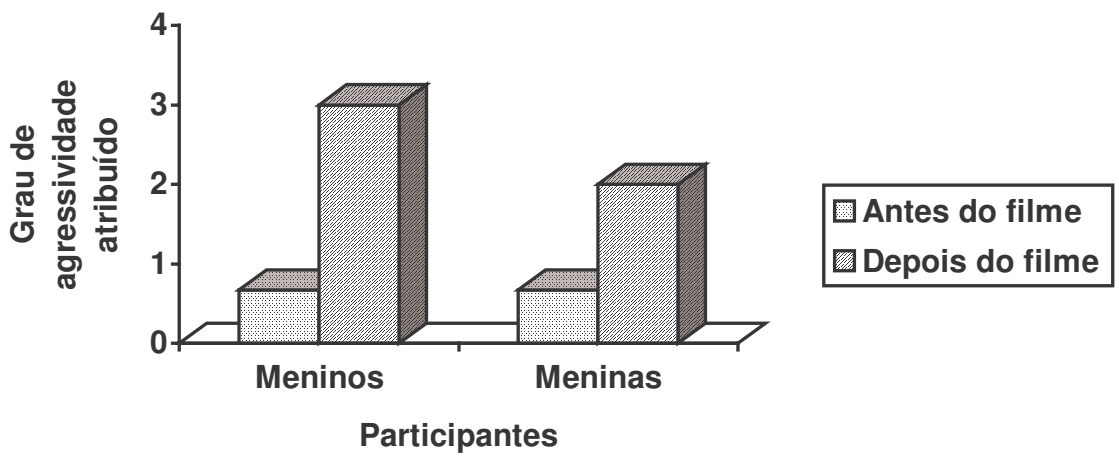

Figura 1: Mediana do grau de agressividade médio atribuído pelos juizes às redações de meninos e meninas, antes e depois de assistirem ao filme Mortal Kombat.

A análise estatística dos dados revelou que existe diferença significante entre o grau de agressividade atribuído pelos juízes às estórias redigidas pelos participantes antes e depois do filme $(\mathrm{W}=957,0 ; \mathrm{p}<$ $0,05)$. Tanto os meninos ( $\mathrm{W}=260,0 ; \mathrm{p}<0,05)$, quanto as meninas $(\mathrm{W}=236,0 ; \mathrm{p}<0,05)$ expressaram mais agressividade nas redações depois de terem assistido ao filme, do que antes da exibição do mesmo, conforme pode ser visualizado na Figura 1. Não se observa diferença, estatisticamente significativa, entre os dados dos meninos e das meninas, antes $(\mathrm{T}=749,5 ; \mathrm{p}>0,05)$ e após o filme $(\mathrm{T}$ $=704,0 ; \mathrm{p}>0,05)$.

A Tabela 1 apresenta as notas atribuídas pelos três juízes às redações de cada participante, podendo-se verificar que as notas variam de juiz para juiz. Entretanto, observa-se que, mesmo havendo variação nas notas, em 18 dos 56 casos (estórias de 18 participantes), os três juízes convergiram quanto ao fato de que o grau de agressividade nas estórias redigidas após o filme aumentou. Notas iguais antes e depois do filme foram apresentadas em três casos; e em outros três casos registram-se notas informando que o grau de agressividade, revelado nas estórias antes e após o filme, havia diminuído. Por conseguinte, em 24 dos 56 casos os três juízes, julgaram o grau de agressividade antes e após os participantes terem assistido o filme com a mesma tendência.

A Figura 2 expressa a tendência das notas dadas pelos três juízes ao se comparar o grau de agressividade, atribuído às estórias redigidas antes e após o filme.

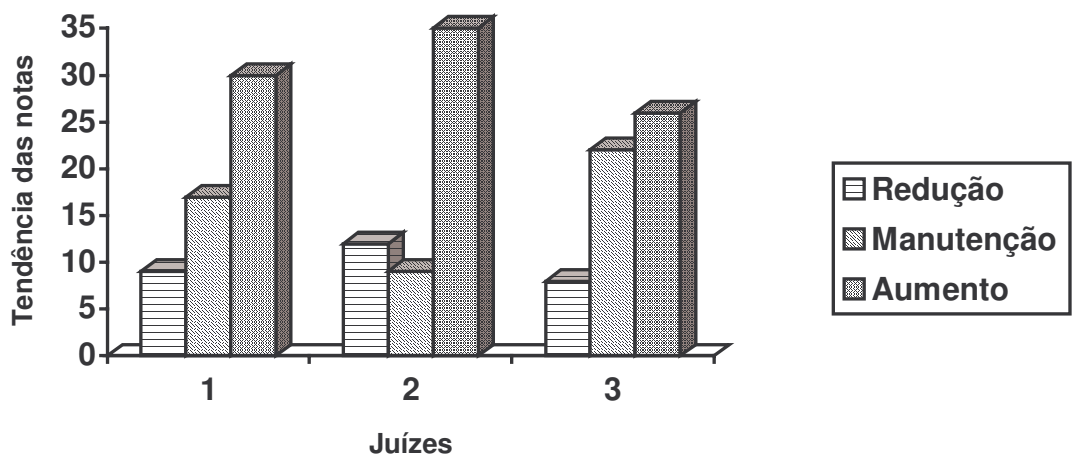

Figura 2: Freqüências na tendência à redução, manutenção e aumento das notas atribuídas pelos três juízes, comparando o grau de agressividade nas estórias redigidas antes e após o filme.

Pode-se verificar, na Figura 2, que os Juízes 1 e 2 apresentam a maior freqüência de notas que indicam uma tendência de aumento no grau de agressividade. O Juiz 2 apresenta a menor frequiência de notas que indicam que o grau de agressividade não foi alterado, enquanto os Juízes 1 e 3 apresentam frequiências aproximadas de notas que indicam que o grau de agressividade foi reduzido. Esses dados não levam, entretanto, em consideração o fato de haver ou não concordância entre os três juízes, aspecto já assinalado anteriormente. Os dados revelam que os três juízes apresentam uma tendência maior a julgar as estórias redigidas após o filme como tendo um conteúdo revelador para eles de um maior grau de agressividade, mesmo tendo-se tido os cuidados de não informá-los quanto ao objetivo do estudo e o de misturar as redações de tal forma, que eles não soubessem qual era a primeira e a segunda redação.

Um outro aspecto a ser considerado com relação às notas atribuídas pelos juízes é que, em alguns casos, a diferença entre as notas é bastante acentuada e em outros casos não. Por exemplo, a estória que o 
Participante 16 redigiu antes do filme recebeu, em termos de grau de agressividade, a nota média igual a 1,33 , enquanto a estória redigida após o filme recebeu nota média igual a 9,00. As redações redigidas antes e após o filme, por esse participante, encontram-se no Anexo 1. Em outros casos, a diferença quanto ao grau de agressividade, atribuído pelos juízes antes e depois de os participantes terem assistido ao filme, foi bem menor. A estória escrita por uma das meninas antes do filme (Participante 18), tomada como exemplo, obteve nota média 5,00 e a que foi escrita após o filme 5,33. Um último aspecto a ser considerado é o fato de que um grande número de estórias (35 antes do filme e 21 depois do filme) recebeu nota igual ou abaixo de 1,0, o que contribuiu, fortemente, para que as notas médias totais fossem baixas, conforme pode ser observado na parte inferior da Tabela 1. Ou seja, apesar de ter havido um aumento significativo nas notas, a nota média total, antes e depois, do filme é inferior a 5.

Tabela 1: Notas atribuídas pelos juízes ao grau de agressividade expresso estórias redigidas pelos participantes antes e após a exibição do filme

\begin{tabular}{|c|c|c|c|c|c|c|c|}
\hline \multirow{3}{*}{ Participantes } & \multirow{3}{*}{ Gênero } & \multicolumn{6}{|c|}{ Notas atribuídas } \\
\hline & & \multicolumn{2}{|c|}{ Juiz 1} & \multicolumn{2}{|c|}{ Juiz 2} & \multicolumn{2}{|c|}{ Juiz 3} \\
\hline & & Antes & Depois & Antes & Depois & Antes & Depois \\
\hline 1 & $M$ & 0 & 1 & 0 & 2 & 0 & 0 \\
\hline 2 & $\mathrm{~F}$ & 0 & 8 & 2 & 10 & 0 & 10 \\
\hline 3 & $\mathrm{~F}$ & 0 & 0 & 0 & 3 & 0 & 0 \\
\hline 4 & M & 3 & 5 & 1 & 2 & 1 & 0 \\
\hline 5 & $\mathrm{~F}$ & 3 & 2 & 0 & 4 & 0 & 4 \\
\hline 6 & M & 2 & 2 & 0 & 0 & 0 & 0 \\
\hline 7 & $M$ & 0 & 3 & 0 & 6 & 0 & 6 \\
\hline 8 & $\mathrm{~F}$ & 4 & 4 & 2 & 1 & 2 & 1 \\
\hline 9 & $\mathrm{~F}$ & 3 & 5 & 3 & 4 & 3 & 5 \\
\hline 10 & $\mathrm{~F}$ & 2 & 0 & 0 & 0 & 0 & 0 \\
\hline 11 & M & 2 & 9 & 0 & 8 & 1 & 6 \\
\hline 12 & $M$ & 0 & 1 & 1 & 0 & 1 & 0 \\
\hline 13 & $\mathrm{~F}$ & 0 & 0 & 2 & 0 & 0 & 0 \\
\hline 14 & $M$ & 0 & 5 & 2 & 4 & 0 & 1 \\
\hline 15 & $\mathrm{~F}$ & 4 & 4 & 4 & 1 & 0 & 0 \\
\hline 16 & $M$ & 0 & 7 & 3 & 10 & 1 & 10 \\
\hline 17 & $\mathrm{M}$ & 5 & 10 & 4 & 10 & 1 & 5 \\
\hline 18 & $\mathrm{~F}$ & 5 & 5 & 5 & 4 & 5 & 7 \\
\hline 19 & $M$ & 2 & 1 & 6 & 0 & 1 & 0 \\
\hline 20 & $F$ & 2 & 3 & 6 & 9 & 0 & 7 \\
\hline 21 & $M$ & 0 & 6 & 0 & 8 & 0 & 5 \\
\hline 22 & $\mathrm{M}$ & 5 & 8 & 0 & 9 & 2 & 7 \\
\hline 23 & $M$ & 0 & 2 & 2 & 6 & 0 & 1 \\
\hline 24 & $F$ & 0 & 4 & 1 & 4 & 0 & 0 \\
\hline 25 & $\mathrm{~F}$ & 0 & 2 & 0 & 2 & 0 & 0 \\
\hline 26 & $M$ & 0 & 0 & 0 & 0 & 0 & 0 \\
\hline 27 & $\mathrm{M}$ & 4 & 3 & 9 & 5 & 7 & 3 \\
\hline 28 & $F$ & 0 & 5 & 0 & 4 & 0 & 5 \\
\hline 29 & $\mathrm{~F}$ & 0 & 0 & 0 & 0 & 0 & 2 \\
\hline 30 & $M$ & 3 & 7 & 2 & 10 & 1 & 5 \\
\hline 31 & $\mathrm{M}$ & 3 & 3 & 0 & 3 & 2 & 4 \\
\hline 32 & $F$ & 4 & 4 & 5 & 6 & 4 & 9 \\
\hline 33 & $\mathrm{~F}$ & 0 & 7 & 0 & 1 & 0 & 4 \\
\hline \multicolumn{8}{|c|}{ cont } \\
\hline \multirow[t]{3}{*}{ Participantes } & Gênero & $\begin{array}{c}\text { Notas } \\
\text { atribuídas }\end{array}$ & 10 & 7 & 9 & 5 & 10 \\
\hline & & Juiz 1 & Juiz 2 & Juiz 3 & 2 & 0 & 0 \\
\hline & & Antes & Depois & Antes & Depois & Antes & Depois \\
\hline 37 & $M$ & 0 & 0 & 0 & 4 & 0 & 1 \\
\hline 38 & $\mathrm{~F}$ & 0 & 2 & 0 & 4 & 1 & 0 \\
\hline 39 & $\mathrm{~F}$ & 10 & 8 & 8 & 8 & 6 & 6 \\
\hline 40 & $\mathrm{~F}$ & 0 & 0 & 1 & 0 & 0 & 0 \\
\hline 41 & $M$ & 0 & 0 & 0 & 3 & 0 & 0 \\
\hline 42 & M & 0 & 1 & 0 & 0 & 0 & 0 \\
\hline 43 & $\mathrm{~F}$ & 0 & 2 & 1 & 3 & 0 & 0 \\
\hline 44 & $M$ & 3 & 7 & 0 & 1 & 0 & 0 \\
\hline 45 & $\mathrm{~F}$ & 0 & 1 & 0 & 2 & 0 & 0 \\
\hline 46 & M & 0 & 0 & 0 & 0 & 0 & 0 \\
\hline 47 & $M$ & 0 & 0 & 0 & 0 & 0 & 1 \\
\hline 48 & $\mathrm{~F}$ & 2 & 1 & 2 & 0 & 1 & 0 \\
\hline
\end{tabular}




\begin{tabular}{c|c|cc|cc|cc}
\hline 49 & $\mathrm{M}$ & 2 & 0 & 0 & 2 & 0 & 0 \\
50 & $\mathrm{M}$ & 3 & 8 & 0 & 9 & 1 & 5 \\
51 & $\mathrm{M}$ & 0 & 0 & 1 & 0 & 2 & 2 \\
52 & $\mathrm{M}$ & 0 & 4 & 0 & 4 & 0 & 4 \\
53 & $\mathrm{M}$ & 0 & 8 & 0 & 10 & 0 & 5 \\
54 & $\mathrm{~F}$ & 0 & 3 & 0 & 3 & 0 & 0 \\
55 & $\mathrm{M}$ & 2 & 0 & 0 & 0 & 5 & 0 \\
56 & $\mathrm{M}$ & 4 & 5 & 6 & 4 & 5 & 6 \\
\hline Total médio & & 1,55 & 3,32 & 1,57 & 3,64 & 1,03 & 2,63 \\
\hline
\end{tabular}

\section{DISCUSSÃO}

De forma resumida, os resultados do presente estudo indicam um aumento no grau de agressividade expresso no enredo de estórias redigidas por crianças após terem assistido ao filme Mortal Kombat. O dados obtidos são semelhantes aos dos dois experimentos conduzidos por Gomide (2000), no que diz respeito ao comportamento dos meninos, mas não em relação ao das meninas. Um aumento no comportamento agressivo das meninas foi observado apenas no Experimento 1, depois de assistirem ao filme Kids, que é um documentário em que são exibidas cenas de abuso sexual de meninas, entre outras formas de violência contra jovens. Esse dado levou Gomide a sugerir que o comportamento de jovens e crianças de sexo feminino tem uma probabilidade maior de ser alterado, quando o filme envolve abusos físico, psicológico ou sexual contra mulheres.

Essa hipótese foi testada em um estudo subsequiente (Gomide \& Sperancetta, 2002), em que adolescentes do sexo feminino, com idades variando de 12 a 18 anos, assistiram ao filme Marcas do Silêncio, no qual uma menina sofre abuso sexual e é tratada com violência pelo padrasto. $\mathrm{O}$ comportamento agressivo das adolescentes foi medido em partidas de futebol, antes e após assistirem ao filme, tendo as autoras verificado um aumento significativo de comportamentos agressivos, durante a partida realizada após o filme. Esses resultados permitem concluir que o tipo de violência exibido nos filmes é uma variável relacionada com o efeito que o mesmo tem sobre o comportamento agressivo de jovens do sexo feminino. Mas, se essa é uma variável relevante, o que pode ter contribuído para que as meninas do presente estudo tenham demonstrado mais agressividade após um filme que não apresenta conteúdos com tais características?

Gomide (2000) observou o comportamento das crianças e dos adolescentes, de ambos os sexos, em partidas de futebol, em que os participantes eram separados pelo gênero, enquanto, no presente estudo, foi avaliado o conteúdo do comportamento verbal expresso pelos participantes no enredo de suas estórias. Esse pode ter sido um dos fatores que contribuiu para a diferença observada nos resultados dos dois estudos. A variável dependente selecionada e constituída para análise pode refletir diferenças relacionadas com a história prévia dos participantes, incluindo o aspecto que se refere ao tipo de comportamento mais freqüentemente reforçado em contextos de vida diária. Por exemplo, Bartholow e Anderson (2002) investigaram o efeito de jogos de videogame sobre o comportamento de jovens, testados em situação de laboratório, nas quais eles podiam punir um outro participante, que era confederado, com estímulos sonoros de diferentes intensidades, durante tarefas que envolviam uma competição. Os rapazes apresentaram uma freqüência maior de punições aos participantes confederados do que as moças. No entanto, o nível de aversividade dos estímulos apresentados (ruídos mais intensos) foi maior no caso delas, quando comparado aos apresentados pelos rapazes. Os autores sugerem que essa e outras diferenças relacionadas ao gênero dos participantes podem ser explicadas com base nos estudos de Björkqvist e cols. (por exemplo, Björkqvist, Lagerspetz \& Kaukianen, 1992; Lagerspetz, Björkqvist \& Peltonen, 1988), os quais demonstram que adolescentes do sexo masculino são mais propensos a passar rasteira, socar, chutar, ou xingar, enquanto adolescentes do sexo feminino, mais freqüentemente mentem, ignoram ou substituem o provocador por um rival. Entretanto, diferenças entre os gêneros, quando se comparam agressões verbais, são menos evidentes e explicadas por Bartholow e Anderson, nesta afirmação: "Em outras palavras, homens provavelmente empregam, com maior frequiência, formas diretas de agressão, enquanto as mulheres usam, com maior frequiência, formas indiretas - ações que são prejudiciais para os outros de maneiras mais sutis" (p. 288).

Diversos estudos relativos ao efeito da violência na mídia sobre o comportamento de crianças e jovens têm usado medidas indiretas, como pode ser identificado, por exemplo, nos trabalhos de Menandro e Gueiros (1994), Bushman (1995), Anderson (1997), Aluja-Fabrent e Torrubia-Beltri (1998), Anderson e Dill (2000), Kiewitz e Waever (2001), e Anderson, Carnagey e Eubanks (2003). De forma geral, essas medidas indiretas consistem de questionários autoaplicáveis, em que os participantes relatam os seus estilos de interação com as pessoas e/ou seus estados de humor presentes (hostilidade e/ou agressividade). Em alguns estudos, os dados dos questionários são correlacionados com os relatos das preferências quanto ao tipo de filme, música e jogo eletrônico. As escalas de estados de humor são usadas, em outros estudos, como fonte de informação quanto às variáveis dependentes medidas, antes e após o contato dos participantes com algum tipo de mídia com violência.

Bushman (1995), por exemplo, comparou as respostas dadas por participantes a uma escala de estados de humor presentes, em que itens referentes a estados de hostilidade foram medidos por uma escala 
de Likert. As tendências agressivas (trait agressiveness) dos participantes haviam sido, inicialmente, avaliadas por meio de um inventário (Buss-Durkee Hostility Inventory) e correlacionadas com o estado de humor relatado antes e após a exposição a filmes com e sem cenas de violência. Bushman descreve que os participantes que assistiram ao filme com violência relataram maiores níveis de humor agressivo do que os que assistiram ao filme sem violência. Além disso, registrou correlação positiva entre as variáveis "tendências agressivas" e o "estado de hostilidade", quando o filme exibido continha cenas de violência, e a não correlação quando o filme exibido não apresentava cenas de violência. Esses resultados e os de dois outros estudos, relatados por Bushman no mesmo artigo, levaram-no a sugerir que o processo, envolvido nesse tipo de efeito produzido pela mídia, pode ser explicado por meio da Teoria Neo-cognitiva de Bushman. De acordo com essa teoria, "indivíduos com tendências agressivas são mais suscetíveis ao efeito de mídia com violência do que indivíduos com baixa tendência agressiva, porque eles possuem uma rede relativamente ampla de associações agressivas que pode ser ativada por estímulos violentos" (p. 959). Essa proposição explicativa tem fundamentos na Teoria Neo-associativa da Agressão proposta por Berkowitz (1984), de acordo com a qual, assistir violência na mídia pode ativar redes semânticas na memória, aumentando, desse mo-do, o acesso a pensamentos agressivos relacionados.

Apesar de amplamente utilizadas, as medidas indiretas, que se baseiam em relatos verbais, devem ser consideradas com cuidado, pois o grau de confiabilidade e precisão das inferências feitas a partir dos relatos verbais é sujeito a processos de interação complexos que dependem de contingências estabelecidas pela comunidade verbal. A correspondência entre o comportamento verbal e o não-verbal depende da história de reforço de coerência e incoerência entre o dizer e o fazer (Lloyd, 1980; Tunes, 1994; de Rose, 1997, Amorim \& Andery, 2002). A medida indireta de agressividade usada no presente estudo é bastante diferente das que são obtidas por meio de questionários. Ela consistiu de estórias construídas pelos participantes, nas quais personagens fictícios, com nomes ambíguos (que tanto podem ser do sexo masculino quanto do feminino), eram envolvidos em situações de conflito interpessoal. Pode-se questionar até que ponto esse tipo de variável dependente pode ser considerado como sendo uma medida do grau de agressividade gerada pelo filme assistido pelas crianças. A teoria de Berkowitz (1984), que considera a ativação de redes semânticas, é uma possível fonte de explicação. Uma outra, pode ser encontrada nos resultados de um grande número de pesquisas, desenvolvidas na área da Análise do Comportamento, as quais têm produzido evidências em favor da explicação do processo, por meio do qual estímulos arbitrários podem ser relacionados um ao outro, formando classes de estímulos equivalentes. Essas classes são consideradas redes relacionais arbitrárias, das quais participam todos os elementos da contingência que estabelece a relação entre os estímulos (Sidman, 2000).

De acordo com os princípios da Análise do Comportamento, os eventos presentes em contingências que mantêm comportamentos agressivos envolvem os estímulos na presença dos quais o ato de agredir foi emitido e as consequiências que mantêm esse comportamento, como reforços positivos e negativos. Ou seja, o comportamento de agredir é reforçado em determinadas situações, mas não em outras. Ele é diferencialmente reforçado diante dos estímulos discriminativos $\mathrm{S}^{\mathrm{D}}$ e $\mathrm{S}^{\Delta}$ (Skinner, 1981; Sidman, 1995). De forma geral, os estímulos discriminativos têm parte de suas funções determinadas por estímulos condicionais, os quais podem alterar a função dos estímulos discriminativos, de acordo com as contingências de reforço (Sidman, 1986, 2000). Por exemplo, em uma partida de futebol, o comportamento de dar um pontapé no jogador do time adversário, que lhe deu um empurrão, será provavelmente reforçado (aprovado), por exemplo, quando o seu time está perdendo (por exemplo, com um placar de $2 \times 0$ ). No entanto, se o time estiver vencendo, a resposta de dar um pontapé no jogador que o empurrou, provavelmente, não será reforçada. $\mathrm{O}$ placar, neste exemplo, pode ser considerado um estímulo condicional, que estabelece a função discriminativa que o empurrão tem, em uma situação e em outra. Levando em conta que as relações condicionais entre estímulos permitem estabelecer classes equivalentes, pode-se considerar que o placar 2 x 0 e os empurrões passam a ficar relacionados a pontapés e com sinais de aprovação, quando o time está perdendo, mas não quando o time está ganhando. Portanto, empurrões podem fazer parte de diferentes classes de estímulos equivalentes, tendo, por conseguinte, diferentes funções, dependendo dos outros estímulos, com os quais estão relacionados.

O procedimento básico sugerido por Sidman (1986, 2000), que leva à formação de classes de estímulos equivalentes, consiste em ensinar pelo menos duas discriminações condicionais relacionadas, conforme está descrito a seguir, por meio de um exemplo que demonstra como palavras adquirem significados. Diante do desenho de uma bola (A1), a resposta de escolher a palavra impressa bola (B1) e não a palavra impressa casa (B2) é reforçada. Diante do desenho de uma casa (A2), a resposta de escolher a palavra impressa casa (B2) e não a palavra bola (B1) é reforçada. Diante da palavra impressa bola (B1), dizer "bola" (C1) é reforçado e diante da palavra impressa casa (B2), dizer "casa" (C2) é reforçado. Como resultado, temos que: diante do desenho da bola é escolhida a palavra impressa bola e diante da palavra impressa bola é dito "bola"; diante do desenho da casa é escolhida a palavra impressa casa e diante da palavra casa impressa é dito "casa". Após esta sequiência de ensino, que envolveu o estabelecimento das relações entre os estímulos A1 e B1, e entre B1 e $\mathrm{C} 1$; entre $\mathrm{A} 2$ e $\mathrm{B} 2$, e entre $\mathrm{B} 2$ e $\mathrm{C} 2$ é provável que a pessoa selecione, sem treino adicional: A1 de um conjunto de comparações, dado B1 como modelo, ou B1 dado C1 como modelo; A2 de um conjunto de comparações, dado B2 como modelo, ou B2 dado C2 
como modelo. Também é provável que a pessoa selecione: $\mathrm{A} 1$ dado $\mathrm{C} 1$ como modelo, e $\mathrm{C} 1$ dado $\mathrm{A} 1$ como modelo; A2 dado C2 como modelo, e C2 dado A2 como modelo. Além disso, diante de A1 selecionará A1; diante de B1 selecionará B1 e assim por diante. De acordo com Sidman, isto demonstra a formação de classes equivalentes, que devem apresentar as propriedades definidoras de reflexividade, simetria e transitividade.

Ao se testar a transitividade, observa-se que eventos que não foram diretamente relacionados com os estímulos $\mathrm{A}$ e $\mathrm{C}$, do exemplo anterior, passam a compartilhar funções. Um estímulo passa a equivaler ao outro. Esse fenômeno é bastante importante, porque um estímulo novo pode ser relacionado de forma condicional a apenas um dos membros de uma classe equivalente e passar a fazer parte da classe, adquirindo a função que os demais estímulos da classe possuem ou transferindo as suas funções para os demais membros da classe. Além disso, deve-se considerar que discriminações condicionais também podem ser colocadas sob o controle de estímulos, de tal forma que as funções dos estímulos condicionais são determinadas por outros estímulos, os estímulos contextuais. A palavra impressa casa estabelece condição para que a resposta de escolher um desenho de uma casa (residência) seja reforçada. Estímulos contextuais podem, no entanto, estabelecer outro significado para a palavra casa. Ela pode ser uma abertura na roupa, pela qual se passa o botão (a casinha de botão). De forma geral, as pessoas discriminam qual o significado de uma palavra pelo contexto da frase em que a palavra ocorre. Da mesma forma, no exemplo da partida de futebol, um estímulo contextual, como o fato de ser aquele um jogo amistoso, pode alterar a função que um placar negativo de 2 x 0 tem e, desta forma, alterar a relação de contingência entre empurrões, pontapés e suas conseqüências.

Para aplicar o paradigma da equivalência de estímulos à análise do processo de como a mídia com violência pode contribuir para o desenvolvimento e a manutenção de comportamentos agressivos, deve-se considerar que estímulos como, cenas de violência, músicas com conteúdos violentos, objetos ou imagens de objetos usados para praticar violência e outros eventos ambientais, assim como, o próprio comportamento agressivo motor e/ou verbal podem vir a fazer parte de classes equivalentes. Essas classes são consideradas como sendo estabelecidas por uma história de reforço diferencial, que envolve discriminações condicionais relacionadas, as quais também podem ficar sob o controle de estímulos. No exemplo da partida de futebol, pode-se aventar que um filme com cenas de violência pode alterar a função que um estímulo condicional, como uma "partida amistosa", tem e, conseqüentemente, alterar a função dos empurrões, os quais passam a significar agressão ao invés de colisões acidentais.

Esse paradigma permite, ainda, compreender como estímulos verbais podem fazer parte de classes equivalentes, formando redes relacionais, e como estímulos contextuais podem determinar a função que esses estímulos verbais possuem. Por conseguinte, pode-se argumentar que relatos de estórias podem fazer parte de redes relacionais que compõem classes de estímulos, que incluem comportamentos agressivos. Portanto, se essas estórias estiverem participando de redes desse tipo, pode-se considerar as mesmas como variáveis dependentes apropriadas para medir o grau de agressividade dos participantes nos estudos.

A descrição de como o paradigma da equivalência de estímulo pode ser aplicado à análise do comportamento agressivo estimulado pela violência na mídia está sendo apresentada aqui de forma bastante resumida e deve ser interpretada como sendo de cunho especulativo. Certamente, evidências empíricas, que fundamentem a presente análise, devem ser buscadas e testes devem ser realizados para demonstrar se estórias relatadas, como as utilizadas no presente estudo, fazem parte de classes equivalentes com outros eventos, incluindo, por exemplo, estímulos apresentados na tela da TV. Além disso, convém destacar que o processo de formação de classes equivalentes, isoladamente, não pode ser considerado como o único fator que contribui para o desenvolvimento e a manutenção de comportamentos agressivos. A maioria dos autores que analisam o comportamento agressivo (por exemplo, Anderson \& Bushman, 2002; Gomide, 1996; Johnson, 1979; Menandro, 1978) concorda em considerá-lo, assim como os demais comportamentos, como multideterminado. Ou seja, a ser explicado apenas por modelos que considerem diversos fatores ao estabelecer as possíveis relações causais entre fenômenos.

O modelo proposto por Anderson e Bushman (2002), denominado Modelo Geral de Agressão (General Agression Model), é baseado em teorias e modelos anteriormente propostos, como, por exemplo, no Modelo da Aprendizagem Social de Bandura (1973), na Teoria Neo-associativa da Agressão de Berkowitz (1984), na Teoria Neo-cognitiva de Bushman (1995), no Modelo Geral Afetivo de Agressão de Anderson e Dill (2000), e em outros. Esse modelo (Modelo Geral de Agressão) propõe que o comportamento agressivo é desempenhado com base na ativação e na aplicação de estruturas de conhecimentos relacionados à agressão, armazenados na memória (por exemplo, sripts e esquemas). Essas estruturas incluem atitudes e crenças agressivas, esquema perceptivo agressivo, esquema de expectativa agressiva, scripts comportamentais agressivos e dessensibilização da agressão. As estruturas de conhecimento social se desenvolvem ao longo do tempo, por meio de processos de aprendizagem, contribuindo para o desenvolvimento de formas específicas de perceber, interpretar, julgar e responder a eventos do ambiente físico e social, de tal forma que cada episódio de violência vivenciado "(...) é essencialmente, uma tentativa a mais de aprender que o mundo é um lugar perigoso, que a agressão é uma forma apropriada de lidar com conflito e o medo, e que a agressão funciona" (Bushman \& Anderson, 2002, p. 1680). 
Mattaini (1996, 1999), também, propõe um modelo de análise que pode ser aplicado à análise da agressividade e que leva em consideração uma série de fatores na origem e na manutenção desse comportamento e ao qual se ajusta a explicação da transferência de função por meio de classes de estímulos equivalentes apresentada acima. De acordo com sua proposta, uma ação violenta, assim como os demais comportamentos humanos complexos devem ser analisados, tal como sugerido por Skinner (1981), com base em fatores biológicos, comportamentais e culturais. Os fatores biológicos estão relacionados com variáveis genéticas, devendo-se considerar os aspectos que foram determinados por seleção natural, como, por exemplo, os que operam em níveis de hormônios e neurotransmissores. Além dos aspectos fisiológicos, deve ser levada em consideração, a eliciação de respondentes incondicionais, cuja origem também está na história filogenética do indivíduo. Mattaini destaca, no entanto, que as rápidas mudanças observadas na incidência de comportamentos violentos de pessoas que vivem em sociedade não podem ser explicadas por mudanças genéticas, pois os genes não mudam com a mesma velocidade.

O destaque feito por Mattaini (1999) é uma das questões amplamente discutida por etólogos. Os homens não sendo dotados de armas naturais, mas de capacidade para criar armas, usam o produto de recursos tecnológicos para agredir e matar, sendo estas armas muito mais letais e devastadoras do que aquelas que a "natureza" poderia ter propiciado a eles.

\begin{abstract}
Lorenz argumentou que, pelo fato de o homem não ter desenvolvido especializações mortíferas, também não desenvolveu inibições elaboradas e controles a respeito de quando não matar. (...) $O$ curso vagaroso da evolução não conseguiu acompanhar o passo dos talentos humanos para elaborar novas armas e, portanto, a capacidade mortífera adquirida pelo homem não se combinou a inibições apropriadas (Johnson, 1979, p. 12).
\end{abstract}

Na proposta de Mattaini (1999), o segundo aspecto explicativo para o desenvolvimento e a manutenção da agressividade, envolve a analise das contingências operantes: os comportamentos modelados e mantidos por suas consequiências. Ou seja, os comportamentos agressivos, assim como os demais comportamentos operantes são mantidos porque eles produzem efeito no ambiente: as ações que dão certo tendem a ser repetidas e as que não produzem esse efeito são extintas. Em outros termos, um ato de violência que interrompa estimulação aversiva, que afasta pessoas ameaçadoras e/ou produza certas consequiências positivas tende a ser repetido. $\mathrm{O}$ desenvolvimento e a manutenção de comportamentos agressivos depende, então, da história de reforço, punição e extinção a que cada indivíduo foi submetido. Essas relações de contingências envolvem, conforme descrito anteriormente, os estímulos ambientais na presença dos quais os comportamentos dos indivíduos foram reforçados, punidos ou colocados em extinção e esses estímulos quando sob contingências condicionais podem formar classes equivalentes, cujos elementos passam a assumir funções comportamentais compartilhadas.

Por último, Mattaini (1996, 1999) analisa a seleção de comportamentos agressivos no nível cultural. "Atos de violência são freqüentemente modelados e mantidos não somente pela família e os amigos, mas por abrangentes forças culturais, incluindo a cultura das ruas, a mídia e eventos paradoxais como o sistema judiciário" (Mattaini, 1999, p. 8). As práticas culturais podem ser consideradas como comportamentos, os quais são mantidos pelos membros de uma entidade cultural devido às vantagens que estes representam para um dado grupo, processo esse que envolve, na maioria das vezes, o controle por regras, como as regras morais, religiosas, constitucionais etc.

Ao analisar os efeitos de algumas práticas culturais (Mattaini, 1999) levanta a possibilidade de que a mídia com violência pode não afetar o comportamento daqueles que têm um amplo repertório de comportamentos governados por regras. Regras morais e valores sociais que são essenciais para a sobrevivência da cultura. A análise das contingências relevantes para a sobrevivência das culturas foi feita em uma variedade de publicações, Skinner (1953/1981, 1968/1972, 1971/1983, 1974/1982, 1987) e retomada por Abib (2001), o qual enfatizou o papel que a sociedade tem no desenvolvimento humano e a importância da formação de valores éticos e políticos.

Engajar-se em práticas culturais visando à sobrevivência das culturas é envolver-se com valores morais e políticos, o que pressupõe uma tarefa preliminar de formação de autocontrole. Cabe à sociedade, às comunidades, aos grupos sociais, à escola, à família e às pessoas tomarem a si a responsabilidade de formação das crianças $e$ dos jovens nos valores éticos e políticos. Com éfeito, são essas as agências de controle e essas pessoas que ensinam os controles necessários para o desenvolvimento de valores, e é aí que, ao fim e ao cabo, as crianças e os jovens adquirem autocontrole $e$ dessa maneira tornam-se preparados para enfrentar as tarefas relacionadas com a sobrevivência das culturas (Skinner, 1953, 1968, 1974). (Abib, 2001, p. 116).

Os modelos propostos por Anderson e Bushman (2002), e Mattaini (1996 e 1999) mostram quão complexa é essa área de estudos. A produção bibliográfica referente ao efeito da mídia com violência sobre o comportamento agressivo (por exemplo, Bushman \& Anderson, 2001; Gomide, 2000; Gomide \& Sperancetta, 2002; Pennell \& Browne, 1999; Wood, Wong \& Chacher, 1991;) revela que as principais questões de natureza conceitual estão relacionadas com a definição dos termos agressividade e violência. Além disso, não há consenso a respeito de qual é a explicação mais adequada para o fato de os seres humanos se comportarem de forma agressiva. Essa bibliografia permite concluir que não há elementos disponíveis para uma definição universal quanto ao o que considerar agressividade e violência, dadas às práticas culturais diferenciadas de cada grupo investigado. $\mathrm{O}$ 
que é considerado como sendo violência ou agressão para um determinado grupo social não o é, necessariamente, para outro grupo.

As dificuldades metodológicas da área também são muitas. Revisões bibliográficas como as apresentadas por Griffiths (1999), Pennell e Browne (1999), e Anderson e cols. (Anderson \& Bushman, 2001; Bushman \& Anderson, 2001; Anderson, 2002) apontam para questões relevantes como as relacionadas com os tipos de variáveis independente e dependente utilizados em cada estudo, o tipo de metodologia de investigação (estudos de laboratório, correlacionais, longitudinais e meta-análises), entre outras. Essas questões culminam em discussões quanto à validade interna e externa dos estudos, como a apresentada por Anderson e Bushman (1997), pela qual a validade externa dos estudos de laboratório é comparada à dos estudos "de vida real". Além dessas questões, há uma série de outros fatores a serem considerados, como, por exemplo, os efeitos de duração da variável independente, isto é, se a mídia com violência afeta o comportamento a curto ou a longo prazo; e de variáveis situacionais, como, por exemplo, temperatura, diferenças relacionadas ao gênero, níveis de provocação que potencializam a ocorrência de agressão; variáveis individuais determinadas pela história genética e de vida dos participantes etc. Todos estes problemas e dificuldades, que não são exclusivos dessa área de estudos, são exacerbados pelo conflito provocado entre os dados de pesquisas e interesses econômicos. Há um segmento da sociedade que se beneficia com o fato de a violência na mídia ser um mercado bastante rentável e eles não estão preocupados com os efeitos que isso possa ter na sobrevivência da cultura.

$\mathrm{O}$ presente estudo mostrou o efeito que assistir a um filme com cenas de violência tem sobre o comportamento agressivo de crianças, medido por meio dos enredos de estórias redigidas por essas crianças logo após o filme. Verificou-se que houve um umento significativo no grau de agressividade expresso nas redações, tanto no caso dos meninos quanto no das meninas. Propôs-se ainda, considerar a formação de classes de estímulos equivalentes como um dos processos envolvidos no efeito da mídia no desenvolvimento e na manutenção de comportamentos agressivos. Essa análise é preliminar e, portanto, especulativa e deve ser testada para que possa vir a ser utilizada como um dos fatores de um modelo explicativo. Além disso, sugere-se que diante das peculiaridades das contingências culturais presentes em nosso país, dados empíricos sobre as práticas culturais e o efeito da mídia com violência no comportamento desses usuários devem ser buscados.

\section{Referências}

Abib, J. A. D. (2001). Teoria moral de Skinner e desenvolvimento humano. Psicologia: Reflexão e Crítica, 24(1), 107-117.

Aluja-Frabegat, A. \& Torrubia-Beltry, R. (1998). Viewing of mass media violence, perception of violence, personality and academic achievement. Personality and Individual Differences. 25, 973-989.
Anderson, C. A. (1997). Effects of violent movies and trait hostility on hostile feelings and aggressive thoughts. Aggressive Behavior, 23, 161-178.

Anderson, C. A. (2002). Violent video games and aggressive thoughts, feelings, and behaviors. Em S. L. Calvert; A. B. Jordan, \& R. R. Cocking (Orgs.), Children in the digital age (pp. 101-119). London: Praeger.

Anderson, C. A. \& Bushman, B. J. (1997). External validity of "trivial" experiments: the case of laboratory aggression. Review of General Psychology, 1(1), 19-41.

Anderson, C. A. \& Bushman, B. J. (2001). Effects of violent video games on aggressive behavior, aggressive cognition, aggressive affect, physiological arousal, and prosocial behavior: a meta-analytic review of the scientific literature. Psychological Science, 12(5), 353-359.

Anderson, C. A. \& Bushman, B. J. (2002). Human aggression. Annual Reviews Psychology, 53, 27-51.

Anderson, C. A.; Carnagey, N. L. \& Eubanks, J. (2003). Exposure to violent media: the effects songs with violent lyrics on aggressive thoughts and feelings. Journal of Personality and Social Psychology, 84, 960-971.

Anderson, C. A. \& Dill, K. E. (2000). Video games and aggressive thoughts, feelings, and behavior in the laboratory and in life. Journal of Personality and Social Psychology, 78(4), 772-790.

Amorim, C. \& Andery, M. A. (2002). Quando esperar (ou não) pela correspondência entre comportamento verbal e comportamento não-verbal. Em H. J. Guilardi; M. B. B. P. Madi; P. P. Queiroz \& M. C. Scoz. (Orgs), Sobre comportamento e cognição: contribuições para a construção da teoria do comportamento (v. 10, pp. 37-48). São Paulo: ESETec.

Bandura, A. (1973). Aggression: a social learning analysis. Englewood Cliffs: Prentice Hall.

Bartholow, B. D. \& Anderson, C. A. (2002). Effects of violent video games on aggressive behavior: potential sex differences. Journal of Experimental Social Psychology, 38, 283-290.

Berkowitz, L. (1984). Some effects of thoughts on anti- and prosocial influence of media events: A cognitive neoassociation analysis. Psychological Bulletin, 95, 410-427.

Bushman, B. J. (1995). Moderating role of trait aggressiveness in the effects of violent media on aggression. Journal of Personality and Social Psychology, 69(5), 950-960.

Bushman, B. J. \& Anderson, C. A. (2001). Media violence and the American public: Scientific facts versus media misinformation. American Psychologist, 56(6/7), 477-489.

Bushman, B. J. \& Anderson, C. A. (2002). Violent video games and hostile expectations: a test of the general aggression model. Personality and Social Psychology Bulletin, 28(12), 1679-1686.

Björkqvist, K.; Lagerspetz, K. M. J. \& Kaukiainen, A. (1992). Do girls manipulate and boys fight? Developmental trends in regard to direct and indirect aggression. Aggressive Behavior, $18,117-127$.

Comstock, G. \& Strasburger, V.C. (1990) Deceptive appearances: television violence and aggressive behavior. Journal of Adolescent Health Care, 11, 31-44.

De Rose, J. C. C. (1997). O relato verbal segundo a perspectiva da análise do comportamento. Em R. A. Banaco (Org.), Sobre comportamento e cognição: questões teóricas, metodológicas $e$ de formação em análise do comportamento e terapia cognitivista (v. 1, pp. 148-163). São Paulo: ARBytes.

Dill, K. E. \& Dill, J. C. (1998). Video game violence: A review of the empirical literature. Aggression and Violent Behavior, $3(4), 407-428$. 
Freedman, J.L. (1984). Effect of television violence on aggressiveness. Psychological Bulletin, 96, 227-246.

Gomide, P. I. C. (1996). Agressão humana, Torre de Babel, 3, 71 87.

Gomide, P. I. C. (2000). A influência de filmes violentos em comportamento agressivo de crianças e adolescentes. Psicologia: Reflexão e Crítica, 13, 127-141.

Gomide, P. I. C. (2002). Crianças e adolescentes em frente à TV: o que e quanto assistem de televisão. Revista Psicologia Argumento, 19, 17-28.

Gomide, P. I. C. \& Sperancetta, A. (2002). O efeito de um filme de abuso sexual no comportamento agressivo das adolescentes. Interação em Psicologia, 6(1), 1-11.

Griffiths, M. (1999). Violent video games and aggression: A review of the literature. Aggression and Violent Behavior, 4(2), 203-212.

Hughes, J. N. \& Hasbrouck, J. E. (1996). Television violence: implications for violence prevention. School Psychology Review, 25(2), 134-151.

Johnson, R. N. (1979). Agressão no homem e nos animais. Rio de Janeiro: Interamericana.

Kiewitz, C. \& Weaver, J. B. (2001). Trait aggressiveness, media violence, and perceptions of interpersonal conflict. Personality and Individual Differences, 31, 821-835.

Lagerspetz, K. M. J.; Bhorkqvist, K. \& Peltonen, T. (1988). Is indirect aggression typical of females' gender differences in aggressiveness in 11 to 12-year-old children? Aggressive Behavior, 14(6), 403-414.

Lloyd, K. E. (1980). Do as I say, not as I do. New Zealand Psychologist, 9(1), 1-8.

Lourenço, E. \& Jinzenji, M. Y. (2000). Ideais das crianças mineiras no século XX: mudanças e continuidades. Psicologia: Teoria e Pesquisa, 16(1), 41-48.

Mattaini, M. A. (1996). Envisioning cultural practices. The Behavior Analyst, 19(2), 257-272.

Mattaini, M. A. \& Lowery, C. T. (1999). Youth violence prevention: The state of the science. Obtido em 27 de agosto de 2003 do World Wide Web: http://www.bfsr.org/ violence.html.

Menandro, P. (1978). Comportamento agressivo: problemas de definição. Psicologia, 4, 1-18.

Menandro, P. R. M. \& Gueiros, G. A. (1994). Concepções de locadores de filmes de agressão retaliadora sobre violência. Cadernos de Pesquisa da UFES, 3(4), 4-13.

Paik, H. \& Comstock, G. (1994). The effects of television violence on antisocial behavior: A meta-analysis. Communication Research, 21(4), 516-546.

Pennell, A. E. \& Browne, K. D. (1999). Film violence and young offenders. Aggression and Violent Behavior, 4(1), 13-28.

Sidman, M. (1986). Functional analysis of emergent verbal classes. Em T. Thompson \& M. D. Zeiler (Orgs), Analysis and integration of behavioral units (pp. 213-245). New Jersey: Erbaum.

Sidman, M. (1995). Coerção e suas implicações. Campinas: Editorial Psy.

Sidman, M. (2000). Equivalence relations and reinforcement contingency. Journal of the Experimental Analysis of Behavior, 74(1), 127-146.

Skinner, B. F. (1972). Tecnologia do ensino. São Paulo: Helber.
Skinner, B. F. (1981). Ciência e comportamento humano. São Paulo: Martins Fontes.

Skinner, B. F. (1982). Sobre o behaviorismo. São Paulo: Cultrix.

Skinner, B. F. (1983). O Mito da liberdade. São Paulo: Summus.

Skinner, B. F. (1987). Upon further reflection. Englewwod Cliffs: Prentice Hall. 
Zavaschi, M. L. S. (Org.) (1998) A Televisão e a violência: impacto sobre a criança e o adolescente. Obtido em 07 de março de 2003 do World Wide Web: http://www.ufrgs.br/ psiq/cip.html

Thompson, K. M. ScD \& Haninger, K. (2001). Violence in Erated video games. The. Journal of the American Medical Association, 286(5), 591-598.

Tunes, E. (1994). Considerações a respeito dos relatos verbais como dados. Psicologia, 10(1), 1-10.

Villani, S. M. D. (2001). Violence in the media. Journal of the American Academy of Child \& Adolescent Psychiatry, 38(10), 1208.

Werthein, J. (1999). Violência na mídia. Discurso proferido no lançamento dos livros "A criança e a violência na mídia" e
"Inocência em perigo" em Brasília, DF. Obtido em 08 de março de 2003 do World Wide Web: http://www.unesco.org. br/noticias/discurso/ap.asp.

Wood, W.; Wong, F. Y. \& Chachere, G. (1991). Effects of media violence on viewers' aggression in unconstrained social interaction. Psychological Bulletin, 109(3), 371-183.

Yokota, F. M. S. \& Thompson, K. M. ScD (2000). Violence in Grated animated films. The Journal of the American Medical Association, 283(20), 2716-2720.
Enviado: 15.11.2003

Revisado: 20.06 .2004 Aceito: 30.06 .2004

\section{Notas:}

${ }^{1}$ Pesquisa encomendada pelo Ministério da Justiçado Estado do Rio Grande do Sul e pela UNESCO ao RETRATO (parte qualitativa realizada nas cidades do Rio de Janeiro, São Paulo, Porto Alegre, Goiânia, Recife e Uberlândia, junto a pais ou responsáveis por crianças e/ou adolescentes, com dois filhos ou mais na faixa etária 8 e 17 anos, das classes sócio-econômicas B e C e crianças das classes sociais B, C e D+, que tivessem irmãos na mesma faixa etária) e ao IBOPE (parte quantitativa - que entrevistou 2.000 maiores de 30 anos, residentes em domicílios com TV e que tinham pelo menos uma criança entre 8 e 17 anos).

${ }^{2}$ Não foram considerados, na presente análise, dados bibliográficos de livros publicados nos EUA que são muitas, nem tão pouco as fontes sobre dissertações e teses.

${ }^{3}$ Scielo é uma base de dados brasileira de publicações científicas multidisciplinares.

${ }^{4}$ INDEXPSI é uma base de dados brasileira de publicações científicas em periódico da área de Psicologia.

${ }^{5}$ Agradecemos a Dr ${ }^{a}$ Paula Inez da Cunha Gomide pela sugestão deste procedimento.

\section{Sobre os autores:}

Ana Presicla Batista: graduação $5^{\circ}$ ano Psicologia - UEL

Lídia Fukahori: graduação $5^{\circ}$ ano Psicologia - UEL

Verônica Bender Haydu: docente do Departamento de Psicologia Geral e Análise do Comportamento da Universidade Estadual de Londrina - UEL - Endereço eletrônico: haydu@ brturbo.com 


\section{Anexo 1}

Estória redigida pelo Participante 16, antes o filme Mortal Kombat.

"Cacá foi passar alguns dias na casa de uma tia desconhecida e era muito grande a sua curiosidade para conhecer aquela casa enorme. Percorreu todos os cômodos e ao entrar no porão percebeu que o trinco quebrou e a porta ficou trancada, então..." (Enunciado 1). Ela começou a bater na porta, gritar e ninguém conseguia ouvir porque a casa era muito grande. Aí ela achou um martelo e ferramentas e começou a bater. Ela conseguiu abrir a porta e quando desceu a escada ela se perdeu e, então, percorreu a casa inteira e achou a tia desconhecida. A tia falou: - Onde você estava? Ela respondeu: - Perdida na sua casa. Então ela e a tia dormiram porque já era muito tarde. No outro dia ela desceu para tomar café e foi embora com sua mãe e seu pai, e contou a eles sua aventura. No meio do caminho a tia apareceu na frente do carro e cobrou a porta, os pais da menina tiveram que pagar tudo. Ela recebeu um castigo e ficou um mês no porão sem sair.

Estória redigida pelo Participante 16, após o filme Mortal Kombat.

"Os pais de Tatá tiveram que fazer uma longa viagem, e a criança teve que passar algum tempo em uma creche onde..." (enredo 2). Todo mundo lá é mau e onde se fizer qualquer coisa apanha. Um dia Tatá foi tentar fugir e um menino, Lucas, viu e rapidamente correu para avisar Lílian, a diretora da creche, que correu e pegou Tatá. Ele apanhou de chicote e ficou com um monte de corte, todo cheio de sangue, e ainda não recebeu nenhum tratamento. Passaram trinta anos e Tatá já estava grande, Lílian estava velha de bengala e Lucas também já estava grande. Tatá queria se vingar de Lílian e Lucas e pegou um facão para esfaqueá-los. Tatá viu Lílian tomando um cafezinho e Tatá pegou o facão e enfiou bem no peito dela e ela morreu na hora. Tatá falou: - Agora é a vez de Lucas! Lucas estava no pátio jogando bola sozinho e Tatá chegou por trás e deu uma facada nas costas dele, e Lucas morreu. Depois Tatá se matou também

\section{Anexo 2}

Estória redigida pela Participante 16, antes do filme Mortal Kombat.

Cacá foi passar alguns dias na casa de uma tia desconhecida e era muito grande a sua curiosidade para conhecer aquela casa enorme. Percorreu todos os cômodos e ao entrar no porão percebeu que o trinco quebrou e a porta ficou trancada, então... (enredo 1). Ela começou a gritar: - Tia me ajuda, eu fiquei presa no porão, o trinco da porta quebrou e não abre. Sua tia era nova, tinha 22 anos e escutou seu chamado e disse: - Agora você vai ter que esperar porque eu disse para não entrar no porão e fechar a porta, o trinco está estragado. Mas ela mexeu e não conseguiu abrir e gritou novamente: - Mas titia aqui está cheirando barata. Ela respondeu: - Tá bem! Já vou, mas não grite novamente. - Venha rápido se não eu desmaio! Sua tia foi lá, abriu a porta e Cacá saiu correndo, se não ela desmaiava. Mas ela correu tanto que sua tia até ficou assustada porque ela nunca viu uma pessoa correr tanto igual a sua sobrinha. Ela saiu gritando "Cacá" e a encontrou e disse: - Você é doida de sair correndo igual uma doida.

Estória redigida pela Participante 18, após o filme Mortal Kombat.

"Os pais de Tatá tiveram que fazer uma longa viagem e a criança teve que passar algum tempo em uma creche onde..." (enredo 2). Ela brigou muito com os coleguinhas. A primeira briguinha foi com Cacá, aquela menininha que ficou presa no porão, na casa de sua tia. Elas se bateram muito, mas não se machucaram. A segunda foi com Mario Brods's que atentou Tatá. Mas a terceira foi para valer, Tatá apanhou até dizer chega, ele dizia: - Não, por favor, pára, eu estou sem fôlego, agora eu acho que vou desmaiar. Mas Mario não escutou, só foi lhe dando murro e soco, Tatá ficou todo sujo de sangue, mas quando a dona da creche viu aquilo, deu um berro e tanto: - Mario, por que bater no menino, é a primeira vez que ele vem na creche e você faz isso? Mas que covarde!!! Mário pediu desculpa e os dois brincaram. 